\title{
Analysis of prostate needle biopsy in patients visiting B \& B hospital: a three year retrospective study
}

\author{
Baidya $\mathrm{R}^{1}$, Sigdel B ${ }^{1}$, Shrestha $\mathrm{S}^{1}$, Baidya $\mathrm{NL}^{2}$ \\ ${ }^{I}$ Department of Pathology, B and B Hospital, Gwarkho,Lalitpur Nepal \\ ${ }^{2}$ Department of General Surgery, B and B Hospital, Gwarkho, Lalitpur, Nepal
}

\section{Keywords:}

Prostate cancer; Prostate specific antigen

\begin{abstract}
Background: Prostate cancer is the most common cancer in men. Prostate specific antigen is a key tumor marker to screen for prostate cancer. However, controversy exits regarding the impact of prostate cancer screening.
\end{abstract}

Materials and Methods: This was a retrospective study carried out in the Department of Histopathology of B and B Hospital during a period of 2 years from 01-05-2064 to 01-05-2066. The study included 26 cases of prostate needle biopsy specimens.

Results: The more common age group $(43.9 \%)$ was $70-79$ years followed by the age group above 80 years old $(7.5 \%)$. The most common benign lesion observed was benign prostatic hyperplasia (5 out of $11,45.45 \%$ ), followed by benign prostatic hyperplasia with chronic prostatitis ( 3 out of $11,27.27 \%$ ). The most common malignant types of lesion encountered was prostatic adenocarcinoma with an incidence of $84.62 \%$ (11 out of 13 cases), following nodular hyperplasia of prostate with low grade prostatic intraepithelial neoplasm $15.38 \%$ ( 2 out of 13 cases). Among the benign and the malignant cases serum PSA ranged from 0 - $\geq 10.1 \mathrm{ng} / \mathrm{ml}$.

Conclusion: Serum PSA value has significant role in the diagnosis of malignant prostatic lesions. However, Histological diagnosis still remains the gold standard for the diagnosis of prostatic cancer.

\section{INTRODUCTION}

Prostate is a glandular organ in males, enveloped by a fibromuscular layer. A conglomerate of lesions affects this organ, among which benign prostatic hyperplasia (BPH), chronic prostatitis, prostatic intraepithelial neoplasm (PIN) and prostate cancer are the leading cause of morbidity in the middle aged and elderly males. ${ }^{1}$

\section{Correspondence:}

Dr. Reena Baidya, MD

Department of Pathology, B and B Hospital, Gwarkho, Lalitpur, Nepal

E-mail: reenashrestha@hotmail.com
Chronic prostatitis is more common than acute prostatitis and is the "black sheep" of the prostate family of disease, because of the difficulty to completely treat such a disease. ${ }^{2}$

Prostatic Intraepithelial Neoplasia is characterized by cellular proliferations within pre-existing ducts and glands with cytologic changes mimicking adenocarcinoma but lacking stromal invasion.

Prostate Cancer is the most common urological malignancy and is second only to lung cancer as a leading cause of cancer related deaths in men. The combination of digital 
rectal examination (DRE), transrectal ultrasonography and serum prostate specific antigen (PSA) represents a powerful diagnostic trend for the detection of early prostatic cancer.

\section{MATERIALS AND METHODS}

Twenty six cases of core needle prostatic biopsies were received from the Surgery Department of B\&B Hospital during the period 18-08-2007 to 17-05-2009. The specimens were received in $10 \%$ formalin and were routinely processed and $4-5 \mu \mathrm{m}$ sections were cut from the paraffin embedded tissue blocks. The sections were stained with Hematoxylin and Eosin. Light microscopic study was done to look for features of BPH, chronic prostatitis (fig.1), PIN, prostatic adenocarcinoma (fig.2) and other changes.

Two cases were excluded from the study, due to inadequacy. The histopathological features of the various benign and malignant lesion in the prostate was analyzed and compared and correlated the serum PSA values.

\section{RESULTS}

In the present study 26 cases of prostatic core needle biopsies were selected. Among the 26 cases, two were inadequate. Therefore the actual number of cases studied was 24 .

\section{Age distribution}

The ages ranged between 30-94 years and the mean age was 62 years. The youngest patient ( 30 years old male) presented with BPH and the oldest patient (94 years old male) with acute on chronic Prostatitis. The more common age group $(43.9 \%)$ was $70-79$ years followed by the age group above 80 years old $(7.5 \%)$.

\section{Incidence disease}

Among 24 cases 11 cases $(45.83 \%)$ were benign including inflammation and 13 cases $(54.17 \%)$ were malignant. The most common benign lesion observed was BPH (5 cases; $45.45 \%$ ), followed by BPH with chronic prostatitis ( 3 cases; $27.27 \%$ ), chronic prostatitis (2cases; $18.28 \%$ ) and acute on chronic prostatitis (1 case; 9\%). The age-wise distributions in benign and malignant lesions are shown in table 1.

Among the 13 malignant lesions, the most common types of lesion encountered were prostatic adenocarcinoma with an incidence of $84.62 \%$ (11 cases). It is followed by BPH with low grade PIN 15.38\% (2 cases).

\section{Serum PSA}

Among the benign cases, 5 cases $(45.45 \%)$ had serum PSA ranged from $0-4 \mathrm{ng} / \mathrm{ml}$., in 1 case $(9.10 \%)$ it ranged from $4.1-10 \mathrm{ng} / \mathrm{ml}$ and in 5 cases $(45.45 \%)$ it was $\geq 10.1 \mathrm{ng} / \mathrm{ml}$. Among the malignant cases, in 1 case $(7.69 \%)$ serum PSA values ranged from $0-4 \mathrm{ng} / \mathrm{ml}$. in 2 cases $(15.39 \%), 4.1$ $10 \mathrm{ng} / \mathrm{ml}$. and in 10 cases $(76.92 \%) \geq 10.1 \mathrm{ng} / \mathrm{ml}$.

\section{DISCUSSION}

Core needle biopsy is a good and useful diagnostic modality for the diagnosis of enlarged and nodular prostate gland and those having focal lesion discernible on ultra-sonography. The diagnostic accuracy can be enhanced on correlation with serum PSA values.

The incidence of benign lesions in our study was $45.83 \%$ and $54.17 \%$ were malignant. William et al. studied 225 cases in the age group between 50-89 years, and found an incidence of $87.55 \%$ benign and $12.45 \%$ malignant cases. ${ }^{3}$

In our study, the age range was 30-94 years with mean age of 62 years $46.15 \%$ of malignant lesions were seen in the age group between $70-79$ years and $36.37 \%$ of benign lesions were also seen with the same age group. William et al. found that, the majority of malignant 70-79 years, and $36 \%$ of benign lesions were in the age group between 60-69 years. ${ }^{3}$ In a study by Ronimel et al. 39\% malignant lesions were between $75-79$ years and $75 \%$ benign lesions were in the age group between $65-69$ years. ${ }^{4}$

Both these studies showed that malignant lesions of the prostate were occurring a decade higher than the benign lesions, unlike this study where both occurred in the seventh decade.

The most common benign lesion observed in this study was BPH $(45.45 \%)$, followed by BPH with chronic prostatitis $(27.27 \%)$. In a study by Mittal et al..$^{5}$ of 185 cases of prostatic lesions, the most common lesion was $\mathrm{BPH}$, with an incidence of $74.59 \%$.

In this study the incidence of chronic prostatic alone was $18.28 \%$ and was the most common accompaniment of BPH. In the study by Mittal et al. ${ }^{5}$ the incidence of chronic prostatitis alone was $38.37 \%$ and chronic prostatitis alone

Table 1: Histopathological diagnosis according to age group

\begin{tabular}{lcccccccc}
\hline Type of Lesion & $\mathbf{3 0 - 3 9}$ Years & $\mathbf{4 0 - 4 9}$ Years & $\mathbf{5 0 - 5 9}$ Years & $\mathbf{6 0 - 6 9}$ Years & $\mathbf{7 0 - 7 9}$ Years & $\mathbf{8 0 - 8 9}$ Years & 90-99 Years & Total \\
\hline Benign & $1(9.09 \%)$ & - & $\mathbf{2 ( 1 8 . 8 9 \% )}$ & $\mathbf{2 ( 1 8 . 1 8 \% )}$ & $\mathbf{4}(\mathbf{3 6 . 3 7 \%})$ & $\mathbf{1}(\mathbf{9 . 0 9 \% )}$ & $\mathbf{1}(\mathbf{9 . 0 9 \% )}$ & $\mathbf{1 1}(\mathbf{1 0 0 \% )}$ \\
Malignant & - & - & $2(15.38 \%)$ & $4(30.78 \%)$ & $6(46.15 \%)$ & $1(7.65 \%)$ & - & $13(100 \%)$ \\
\hline
\end{tabular}


or complicating acute prostatitis was commonly found in association with $\mathrm{BPH}$.

The most common type of malignant lesion encountered in this study was prostatic adenocarcinoma of $84.62 \%$ among all malignant lesions. Two cases of $\mathrm{BPH}$ with low grade PIN was also observed. Roberto et al. reported an incidence of $38.3 \%$ and $40.1 \%$ of prostatic adenocarcinoma and high grade PIN respectively in the core needle biopsy. ${ }^{6}$ This study showed a higher incidence of prostatic adenocarcinoma.

Serum PSA value above the reference range of $0-4 n g /$ $\mathrm{ml}$ was observed in $45.45 \%$ of the benign cases. Benign conditions, such as acute urinary retention, bacterial prostatitis, prostatic ischemic or infarction and BPH can be associated with an elevated serum PSA levels. ${ }^{7}$ There was no significant difference in the incidence of cases between the above mentioned ranges of serum PSA values. Hence, the serum PSA value was not significant in the diagnosis of benign prostatic lesions. Partin et al. showed that serum PSA does not correlate with the volume of benign hyperplasia within the gland. ${ }^{8}$

In this study, there was significant difference in the incidence of cases between the above mentioned ranges of serum PSA values. The median serum PSA value was higher in malignant cases than in benign cases and hence the serum PSA value was more significant in the diagnosis of malignant prostate lesions. A serum PSA $>20 \mathrm{ng} / \mathrm{ml}$ has been associated with cancer detection rates in more than $70 \%$ of cases. Hence, significantly increased PSA is a more reliable tumor marker and a better predictor of prostate cancer.

\section{CONCLUSION}

Both benign and malignant lesions were seen in the elderly individuals and the commonest malignant lesion is prostatic

\section{REFERENCES}

1. Rosai J. Male reproductive system. Prostate and seminal vesicles. In:Junan Rosai, editor. Rosai and Ackerman's Surgical Pathology. $9^{\text {th }}$ ed. Vol 1. Mosby: Missouri;2004.pp1363-88.

2. Curtis NJ. Prostatitis: Myths and realities. Urol 1998;51:362-6.

3. William HC, Mosley BR, Charles LR et al. Clinical application of transrectal ultrasonography and prostate specific antigen in the search for prostate cancer. J Urol 1988;139:758-61.

4. Rommel FM, Victor EA, Joseph $\mathrm{AB}$ et al. The use of prostate specific antigen and prostate specific antigen density in the diagnosis of prostate cancer in a community based urology practice. J Urol 1994;151:88-93.

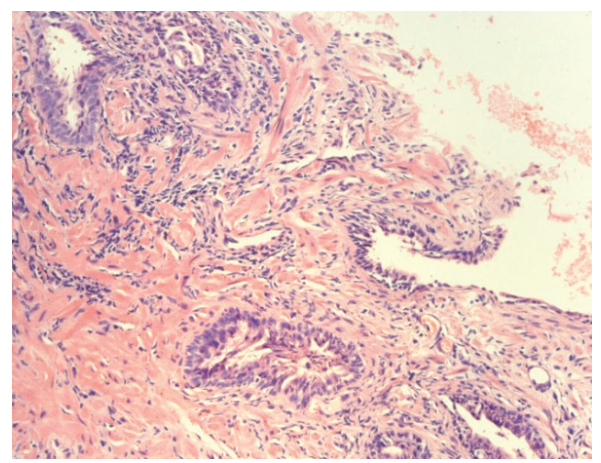

Figure 1: Benign prostatic hyperplasia with chronic prostatitis (HE stain, X200).

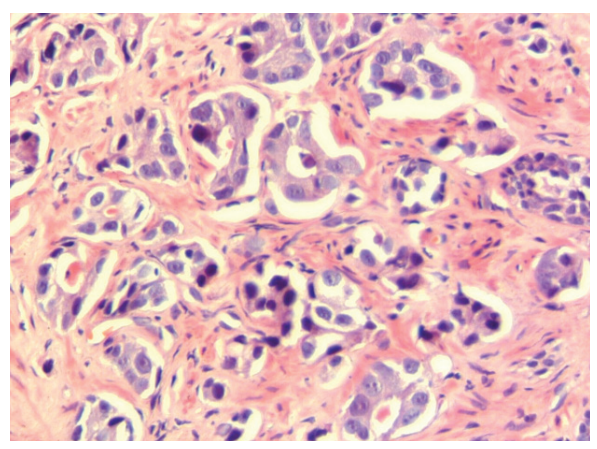

Figure 2: Prostatic Adenocarcinoma (HE stain, X400).

adenocarcinoma. Serum PSA value has significant role in the diagnosis of malignant prostatic lesions. However, Histological diagnosis still remains the gold standard for the diagnosis of prostatic cancer.
5. Mittal BV, Amin MB, Kinare SG. Spectrum of histological lesions in 185 consecutive prostatic specimens. J Post Grad Med 1989;35:15761.

6. Roberto O, Gerard O, Binitha K, Miller MC, Robert WV. Observations on pathology trends in 62,537 prostate biopsies obtained from urology private practices in the United States. Urol 1998;51:186-95.

7. John EM. Normal and pathologic anatomy of prostate. Suppl. Urol 1981;17:11-16.

8. Partin AW, Carter HB, Daniel WC et al. Prostate specific antigen in the staging of localized prostate cancer: Influence of tumor differentiation, tumor volume and benign hyperplasia. J Urol $1990 ; 143: 747-51$ 